\title{
FACTORS OF EMPLOYEES' SATISFACTION IN WORKPLACES FROM A METHODOLOGICAL POINT OF VIEW
}

\author{
Maja Vojinović295
}

https://doi.org/10.31410/itema.2018.812

\begin{abstract}
In this paper we will deal with the theme of employees' satisfaction with their workplace from the methodological point of view. Business satisfaction is one of the most researched topics in the field of people's behavior in organizations. The reason for this is the belief that a worker is a productive worker and that the organization's performance cannot be achieved with dissatisfied employees. In order to anticipate someone's satisfaction with the work, we must take into account not only the satisfaction of certain aspects of the work that the individual is dealing with, but also his expectations of the job. The total satisfaction with the job is caused by a disagreement or deviation of satisfaction from expectations in relation to certain aspects of the job, and not the level of satisfaction with these aspects, by themselves. All satisfaction factors can be grouped into two categories: organizational and personal satisfaction factors.
\end{abstract}

Keywords: factors, satisfaction, employees, workplace, methodology.

\section{INTRODUCTION}

$\mathrm{T}$ The most important among all employees' attitudes is the attitude towards the job. This attitude is called job satisfaction and can be defined as the "cognitive, affective, and evaluative reactions of an individual to his job" (Nadoveza, 2001: 84). Job satisfaction is, therefore, a complex attitude that includes certain assumptions and beliefs about the job (cognitive component), feelings towards work (affective component), and job evaluation (evaluation component). In order to predict someone's satisfaction with the work, we must take into account not only the satisfaction of certain aspects of the work that the individual is dealing with, but also his expectations of the job. The total satisfaction with the job is actually caused by a disagreement or deviation of satisfaction from expectations in relation to certain aspects of the job, and not the level of satisfaction with these aspects, by themselves. All satisfaction factors can be grouped into two categories: organizational and personal satisfaction factors.

Organizational factors of job satisfaction are: job by itself, reward system, pleasant working conditions, colleagues at work and organizational structure. People are more satisfied if they do a job that is mentally more challenging than if they perform a simple, routine job. The challenged job has three characteristics: it enables an employee to perform a variety of tasks, gives freedom of work to the employee, and provides feedback to the employee on how he / she have done the job. Regarding the reward system, it is as if the salary is higher, people are generally more satisfied with the job. It is important to note that the perceived fairness of the reward system is a more important factor than the salary itself.

The more work conditions are, the better the worker satisfaction is. It is bigger not only because it is physically more pleasant to them, but also because better working conditions create a

\footnotetext{
${ }^{295}$ Faculty of Management, Sremski Karlovci, Serbia
} 
greater possibility for better performance of work tasks and success at work. The social atmosphere is also an important factor of satisfaction at work. Employees are more satisfied with their work if they work with colleagues with whom they personally have very good relationships and if a pleasant social atmosphere is at work. Within this factor is also the attitude of the employees with the direct manager (boss).

Personal satisfaction factors are: harmony between personal interests and work, work experience and age, position and status and overall satisfaction with life. More satisfactory jobs are those workers whose personal profile, knowledge and abilities they possess better respond to the needs of the workplace they are in. Older people and people with a higher work experience tend to be more satisfied with work than those with a lower work experience in a particular job. This happens not only because a man becomes better and better in his work and he gives more results during a time, thus he is more rewarded. Actually this happens because of the effect of cognitive dissonance.

Even though, those who were not initially satisfied with their work, if they stayed for a long time, rationalize their calmness by convincing themselves that they are satisfied with this job. The higher the hierarchical level of the employee, the more satisfied he is with the job he deals with. The cause is also certain. The higher incomes, status and certain status symbols: higher power and social influence, the greater is satisfaction with the work. Research has proven the effect of "spilling" (Robins, 2003: 54) of satisfaction. Satisfaction with a lifetime positively reflects on the satisfaction of the job that a person deals with and vice versa, and satisfaction with the job has a positive effect on total satisfaction with life.

Job satisfaction is not the purpose for itself. Although there are more and more theories according to which the social responsibility of a company implies its obligation to satisfy employees, however, most authors deal with this problem, since it starts from the assumption that a more satisfied worker is a more productive worker. Employee satisfaction has three main effects: satisfaction and productivity, absenteeism and fluctuations. It is logical to assume a positive correlation between satisfaction and productivity, although this relationship is not as strong as it used to be. The correlation coefficient in all studies is about 0.17 .

\section{THE LINK BETWEEN EMPLOYEES' SATISFACTION AND PRODUCTIVITY}

There are many reasons why the link between employees' satisfaction and productivity is not stronger and more direct. First, it is possible that other factors, not just employees' satisfaction, are affected by productivity. A possible explanation for the weak correlation of the satisfaction and productivity of the worker is the direction of the cause-effect relationship of these two phenomena. Some studies show that perhaps the increase in productivity is the cause, not the result of employees' satisfaction. Increasing productivity causes performance improvements, which increases employees' rewards, which leads to an increase in their satisfaction. Satisfied workers will be less absent from work. This hypothesis is also confirmed by empirical research, although the (negative) coefficient of correlation is not as strong as expected. It has been found that satisfied workers will leave the job less than dissatisfied, which is very common sense. The fluctuation rate in companies with high employee dissatisfaction is considerably higher than in those with a lower degree of dissatisfaction. 


\section{THE RESULTS OF THE EARLIER RESEARCHES}

According to a survey conducted by the Minnesota Natural Resources Department (Molina, 2007: 68) in the period 2004-2006, on the sample of 850 employees at the Institute for Science and Development in Minnesota, USA, we have come up with results that show that majority of respondents consider it important that their quality work be noted and valued and that they need recognition for their work. Previously mentioned controversy about the factors that drives employees in the direction of greater satisfaction at work, and therefore more efficient and effective solving of tasks is the subject of research of a wide scientific population. Almost all studies agree that different motives trigger different needs, and hence employees' satisfaction differs and depends upon a number of factors that companies respond with appropriate managerial strategies in order to satisfy them.

"Kranet" is an international organization for comparative research in the field of human resources management, founded in 1989, based in England (Šušnjar, 2005: 154). In the research conducted in the period 2003-2005, 7914 organizations from 32 countries participated. From Europe, these are the following countries: Austria, Belgium, Bulgaria, Iceland, Cyprus, Czech Republic, Denmark, Estonia, Finland, France, Germany, Greece, Hungary, Italy, Norway, Slovakia, Slovenia, Spain, Sweden, Switzerland, the Netherlands, Turkey and Great Britain. And from the rest of the world, the participants were: Australia, Canada, Israel, Nepal, New Zealand, Philippines, Tunisia and the United States. Crane research was conducted in the period from 2003 to 2010 and it presents a dominant remuneration practice as the main factor affecting employees' satisfaction in workplaces applied in most European countries (Kranet, 2011: 75). The obtained data confirm Bruder's scientific analysis (Bruster, 2007: 142) according to which modern forms of variable earning are gaining in importance and contributing to the success of the company.

In Japan, business philosophy is largely based on contributions to the wider community and the state. Even in companies where there is no business philosophy, a unique corporate culture has been built, and in fact it represents the unity of thoughts, visions and norms for actions that have been built for years and taught as a tradition of the company. Some of the most common working groups in most Japanese companies are "quality control circles and groups" (Dimitrovski, 2010: 78). Instead of solving some quality problems, Japanese companies are focused on improving the quality of work as a whole, because only in this way can the company achieve its goals.

The results of previous research in Serbia are the following data. In a company called "Faculty of Management", headquartered in Sremski Karlovci, in the period 2011-2014, a team of research associates from the international organization Galup, headquartered in Lisbon, conducted a survey of 92 employees. Generally speaking, employees are very satisfied with the workplace. Observing the aggregate average response values by categories of survey statements, the highest values were obtained in terms of employees' satisfaction with development opportunities and interpersonal relationships.

Then, almost the same high value was obtained in terms of employees' loyalty and their satisfaction with secured working conditions. Then the satisfaction of employees with their own workplace and the way in which corporate communication takes place. As stated above, the highest values were obtained in terms of employee satisfaction with developmental capabilities (Robins, 2003: 98). 
In terms of development opportunities, they have very high values, so it is impossible to say what could be possible points of improvement, except for the recommendation that the company continue to do so. By synthesizing the above mentioned research results, we have come to the conclusion that: evaluation of work, recognition, reward system, corporate culture, development opportunities and interpersonal relationships are key factors that influence the satisfaction of employees with workplaces.

\section{THE SCIENTIFIC IMPORTANCE OF THIS RESEARCH}

The scientific significance of this research is reflected in the fact that it should contribute and complete the fund of scientific knowledge about the factors that influence the satisfaction of employees with their workplace.

The results of the research will be used to provide answers to the questions how the internal and external factors influence the satisfaction of the employees. In addition, the results of this research should provide us with valuable materials for a more complete understanding of the given issues and continuous improvement of the research practice in this plan, so that the information that comes in this way from year to year is becoming more and better for the participating firms. The scientific component of this research completely belongs to the field of human resources management, and partly to other areas of management, such as communication, organizational behavior and change management.

\section{THE SOCIAL IMPORTANCE OF THIS RESEARCH}

The research will have its social significance, as it will point out the very complex problem that is present in society. Only a satisfied worker is a productive worker. The significance of this research is that it will affect changes that can contribute to the improvement of the current situation. This type of research aims to promote and popularize this kind of research with us. The research should provide valuable material for a more complete understanding of the given issues and continuous improvement of the research practice in this plan, so that the information that comes in this way from year to year is becoming more and better for the participating firms. In addition, the social significance of this research is that the best companies in Serbia are recognized and rewarded.

\section{HYPOTHETICAL ATTITUDES ABOUT THE PROBLEM}

The most important among all employees' attitudes is attitude towards their business. This attitude is called job satisfaction and we can define it as "cognitive, affective, and evaluative reactions of an individual to his job". Job satisfaction is, therefore, a complex attitude that includes certain assumptions and beliefs about this business (cognitive component), feelings towards work (affective component), and job evaluation (an evaluative component). Job satisfaction is one of the most explored topics in the field of human behavior in organizations. The reason for this is certainly the belief that a worker is a productive worker and that the organization's performance cannot be achieved with dissatisfied employees.

Therefore, the satisfaction is not affected only by the size of the award, but also by the recipient receiving the award, or whether for the work done, the worker receives those awards he appreciates. According to this theory, workers who have a small salary do not have to be dissatisfied if their pay is not the most important factor of job satisfaction. If, for example, creative, young engineers in development are likely to be satisfied with the job, even if they 
have a small salary, if they have the opportunity for creative work, training, learning and promotion because it is what they value at work. In order, therefore, to anticipate someone's satisfaction with the job, we must involve not only the satisfaction of certain aspects of the work that the individual is dealing with but also his expectations of the job.

The overall satisfaction with the work is really caused by a disagreement or deviation of satisfaction from expectations in relation to certain aspects of the business, and not the level of satisfaction with these aspects themselves. Someone may be dissatisfied with the job even though he has a high salary and is pleased with the salary, if he does not have high expectations regarding the height of the salary itself, but in terms of career progression. Lok's theory draws attention to another important phenomenon. People have the tendency to tie the level of satisfaction to certain aspects of the job to the extent of the discrepancy between expectations and satisfaction. Namely, in those aspects where the lack of expectation and satisfaction is a great and absolute level of satisfaction, the tendency is falling.

\section{THE FACTORS OF JOB SATISFACTION}

Factors can be grouped into two categories: organizational and personal satisfaction factors. The organizational factors include:

1. Job itself. People are more satisfied if they do a job that is mentally more challenging than if they perform a simple, routine job. The challenged job has three characteristics: it enables an employee to perform a variety of tasks, gives freedom of work to the employee, and provides feedback to the employee on how he / she have done the job.

2. Award system. The higher the salaries, employees are generally more satisfied with the job. However, it must be noted immediately that the perceived fairness of the remuneration system is a more important factor than mere salary. This has also been shown in all research carried out in domestic enterprises. Workers are more satisfied if they perceive that the reward system is fair and equally treats all employees. From the fairness of the reward system, the expectations are higher than the salary itself.

3. Pleasant working conditions. The better the conditions of work, the more logical the employee's satisfaction is. It is bigger not only because it is physically more pleasant to them, but also because better working conditions create a greater possibility for better performance of work tasks and success at work. People are often dissatisfied with poor working conditions not so much that they are personally uncomfortable for them because they interfere with them to achieve the expected performance.

4. Colleagues at work. The social atmosphere is an important factor of satisfaction at work. Employees are more satisfied with their work if they work with colleagues with whom they personally have very good personal relationships and if a pleasant social atmosphere is at work. This particularly applies to people who are not much interested in a career. Within this factor is also the attitude of the employees with the direct manager (boss). If the employee has a closer relationship with the boss, if the boss praises the employee more often, follows his work and builds open relationships with him, then the employee' satisfaction is even greater. It should also be noted that national culture can have an impact on the importance of this factor of job satisfaction. In collectivist cultures it is logical to assume that the importance of a pleasant social atmosphere and the absence of conflict is a very important factor of satisfaction with work in most of the employees, even more important than the amount of salary. Some studies show that this is valid for all our companies. In every domestic company, the most important aspects of work, the ones most expected, are in fact related to the social environment: good relations with colleagues, good relations with the boss, absence of 
conflict, socializing with colleagues after work, etc. The conclusion is that the satisfaction with the work of our employees is influenced by the social environment more than the level of salaries, which, among other things, can explain the relatively few strikes and dissatisfaction of workers compared with the size of their standard of living.

5. Organizational structure. Research in the United States has shown that employees are more satisfied if the organization is more decentralized and given more opportunities for participation in decision-making. This argument seems quite logical, but one has to bear in mind the possibility of its cultural limitation. Namely, decentralization can be a source of employee satisfaction only if they have a presumption and expect that power should be as much as possible distributed evenly in the organization. This is, however, the case only in national cultures with a so-called distance of power.

In high-crop cultures, employees do not expect and do not prefer their involvement in decisionmaking, and decentralization is likely to remain unaffected by their satisfaction. Research in our companies has shown that one other feature of the organizational structure is the source of employee satisfaction - transparency and stability. Employees in our companies are more satisfied if the organizational structure is clear, familiar and stable. This can be brought about in connection with another feature of our national culture - the ailing of uncertainty. Our workers do not like change, uncertainty, ambiguity, and it is logical for the structure to expect them to spare them. If it is such, it will be a source of employees' satisfaction, if not a source of dissatisfaction.

\subsection{Personal satisfaction factors}

A fund between personal interests and work. More satisfactory jobs are those workers whose personal profile, skills and abilities that they possess are better suited to the needs of the workplace they are in. In this case, the employee feels that the job allows him to express all his knowledge and skills, to show his personality and abilities, and be more satisfied. The influence of this factor is also indirect. The balance between skills and job requirements will lead to better performance results, these to higher rewards and all together will lead to greater employee satisfaction.

1. Work experience and age. Older people and people with a higher work experience tend to be more satisfied with the job than those with a lower job position. This happens not only because, in time, the man becomes better in his work, he gives more results, he is more rewarded, but also because of the previously described effect of cognitive dissonance. Even those who were not initially satisfied with their work, if they stayed for a long time, they rationalize their passivity by convincing themselves that they are satisfied with the job. Research has shown that job satisfaction is growing with years of seniority and age, but not liner. First, the job satisfaction is rising rapidly through the thirties, because the man is becoming more and more successful in his career and progressing in his career. Around 40 people reach zenith in work, loses many illusions about it, and is less satisfied than in the second half of the fifties and until the retirement, employee will again be happy with work.

2. Position and status. The higher the hierarchical level of the employee, the more satisfied he is with the job he deals with. The cause is also certain that higher positions go with higher incomes, as well as with certain status symbols, greater power and social impact, which leads to higher job satisfaction.

3. Overall satisfaction with life. Research has proven the effect of "spilling pleasure". Satisfaction with the overall life is positively reflected on the satisfaction of the job that 
a person deals with and vice versa, satisfaction with the job has a positive effect on the overall satisfaction of life.

4. Employees' satisfaction with workplaces. While it is logical to assume a strong positive correlation between satisfaction and productivity, this relationship is not as strong as it used to be. The correlation coefficient in all surveys is about 0.17 . There are several reasons why the link between employees' satisfaction and productivity is not stronger and more direct. First, it is possible that other factors are affected by productivity, and not just the satisfaction of the workers. There is a technology where a worker can affect productivity only a little because the technological process determines the speed of work. Employers' satisfaction or dissatisfaction can then slightly affect productivity. A possible explanation for the weak correlation of worker satisfaction and productivity is the direction of the causal link between these two phenomena.

Some studies show that perhaps increasing productivity is a cause rather than a consequence of employees' satisfaction. The increase in productivity results in improved performance and this increase in employees' benefits leads to an increase in their satisfaction. Finally, it has also been shown recently that productivity is only one aspect of improving performance under the effect of employees' satisfaction. A satisfied worker will not only be more productive but will, as it is sometimes important, create a better atmosphere at work and positively affect the work of other colleagues.

Absence from work. Satisfied workers will be less absent from work. This hypothesis was confirmed by empirical research, although (negative) coefficient of correlation is not as strong as expected. The probable cause of a weaker link of employees' dissatisfaction and their absence from work is that other factors have an influence on the decision to leave the work. Sometimes a very satisfied worker must be out of work. On the other hand, there are several factors that force the disgruntled worker to come to work - the fear of losing work, responsibility towards colleagues at work or towards the client.

Fluctuation. It has been found that satisfied employees will leave the job less than dissatisfied, which seems to be very common sense. The fluctuation rate in companies with high employee's dissatisfaction is considerably higher than in those with a lower degree of dissatisfaction. Nevertheless, there are also a lot of median variables that can complicate this relationship. An unhappy worker may remain at work because there are no other options. This means that the correlation of employees' satisfaction and fluctuation is influenced by the general economic conditions and the level of unemployment in the economy. It has also been established that the tendency of abandoning work is also affected by general satisfaction or dissatisfaction with the worker's life. This influence is contrary to what might have been assumed at first glance. Workers who are generally satisfied with life (but dissatisfied with work) are easier to leave than those who are dissatisfied with both work and life as a whole.

\subsection{Factors of productivity and fluctuation}

1. Prior working conditions - If the conditions of work are better, it is logical that the worker's satisfaction is greater. It is bigger not only because it is physically more pleasant to them, but also because better working conditions create a greater possibility for better performance of work tasks and success at work.

2. Organizational structure - many studies have shown that employees are more satisfied if the organization is more decentralized and that employees are given more opportunities to 
participate in decision-making. This argument seems quite logical, but it must also bear in mind the possibility of its cultural limitation.

3. Improving the performance - a satisfied worker will not only be more productive but, as it is sometimes important, creating a better atmosphere at work positively affects the work of other colleagues.

4. Absence from work - satisfied workers will be less absent from work. This fact is confirmed by many empirical researches, although the (negative) coefficient of correlation is not as strong as expected. The probable cause of a weaker link of employees' dissatisfaction and their absence from work is that other factors have an influence on the decision to leave the work.

5. Work experience and age - satisfaction with work grows with years of seniority and age but not linear. First, the job satisfaction is rising rapidly through the thirties, because the man is becoming more and more successful in his career and progressing in his career. Around 40 people reach zenith in work, loses many illusions about it, and are less satisfied that in the second half of the fifties and until the retirement, when they will again be happy with work.

6. Position and status - satisfaction with a lifetime positively reflects on the satisfaction of the job that a person deals with and vice versa, satisfaction with the job has a positive effect on the overall satisfaction of life.

7. Personal dissatisfaction with the employee - personal dissatisfaction can negatively affect the work performance of the employed person.

8. Employees' dissatisfaction - inadequate position or employees' dissatisfaction with what he or she is doing, what they do is badly affecting the job.

The research is interdisciplinary. It will be implemented in the field of human resources management and partly in other areas of management, such as communication, organizational behavior and change management. The survey will be implemented in the period from 2005. to 2015. The research will cover a period of 10 years on the territory of the city of Novi Sad in two companies. The survey will be done on a sample of 10 respondents, 5 women and 5 males.

\section{GOALS OF RESEARCH}

\subsection{Scientific goal of research}

The scientific goal of the research is scientific discovery in a specific research enterprise. Scientific discovery as the objective of this research should contribute to the identification of cause-and-effect relationships that exist between factors that affect the satisfaction of employees with their workplaces, but also to provide new scientific knowledge concerning this problem, and which were not reached by researchers who previously dealt with this issue. Scientific descriptors as the lowest level of scientific knowledge enable us to describe satisfaction factors: a system of rewarding, pleasant working conditions, a job by itself, colleagues at work, organizational structure, etc. which affect employees' satisfaction with their workplace and classify them into two or more categories. (Milosavljevic, 2006). The scientific goal is a theoretical and practical analysis of employees' satisfaction factors in their workplaces. For modern employees, in order to effectively create and work, it is crucial to be satisfied with their employment and the type of work they perform. Therefore, the significance of this research is to draw attention to all the factors that affect employees' satisfaction with their workplace. The future of the company depends on the level of employees' satisfaction and their motivation; therefore, it is of a great importance that every work contributes to the research of this complex area. In fact, by researching methods and techniques that affect employees' satisfaction, we provide an insight into the future trends of the organization's modern business. 


\subsection{Social goal of research}

The social objective of this research is reflected in:

- To examine the extent to which the characteristics of the work and organization are present as a factor of employee's satisfaction,

- Examine the extent to which material compensation and benefits are present as a factor of employee's satisfaction,

- To examine the extent to which the relationship with the superiors and colleagues is present as a factor of employee's satisfaction,

- Examine the extent to which the required competencies are present as a factor of employee's satisfaction,

- Examine the extent to which employees' readiness for additional learning and responsibility is expressed.

\section{RESEARCH METHODS}

In accordance with the scientific goal, the hypotheses and scientific justification of this research, we will primarily deal with the theoretical and practical analysis of the factors of employees' satisfaction with their workplaces. Modern employees should be satisfied with their employment and the type of work they perform. Therefore, the significance of this research is to draw attention to all the factors that affect employees' satisfaction with their workplace. Also, in accordance with the hypothesis and scientific justification where it is assumed that the external and internal aspects of the workplace are present as factors of employees' satisfaction, and if the working conditions are better, in so doing, the productivity of employees will be higher, as the fluctuation will be less if employees are not satisfied with their personal lives. This research is scientifically justified by the fact that it will deepen and complement existing scientific knowledge of factors that affect the satisfaction of employees with their workplaces, but also enable them to reach new scientific knowledge concerning this problem, which were not reached by researchers who had previously dealt with these topics. Therefore, various methods of research will be used in this paper to satisfy the basic methodological requirements: generality, reliability, objectivity and systematicity.

In order to prove the hypothesis, we will use analytical and synthetic methods, a hypotheticaldeductive, comparative and descriptive method. In this paper, we will use a descriptive method to describe the subject and factors we have learned about during the writing process.

We will use the analysis to explain the object of research to its constituent parts, that is, to the factors of structure, function, relationships in a given space and within a certain period of time.

Also, in the paper we will use the hypothetical - deductive method as an experimental method whose cognitive and, in particular, the scientific and cognitive basis of the overall social, organizational and scientific dimension which must be general, tested and verifiable. At the same time, it is changeable and developmental.

For the explanation, comparing identical, similar and different phenomena, we will use a comparative method. In this paper we will use the method of data collection.

The techniques of research that will be used in this paper are the techniques of assignment. The research tool to be used in this paper is a questionnaire. Items in the questionnaire will be 
closed-type questions. When drafting and applying the instruments, the rules of proper design and assignment will be respected. Responding to a questionnaire will be anonymous.

\section{SCIENTIFIC AND SOCIAL EXPLORATION OF RESEARCH}

This research is scientifically justified by the fact that it will deepen and complement existing scientific knowledge of factors that affect the satisfaction of employees with their workplaces, but also enable them to reach new scientific knowledge concerning this problem, which were not reached by researchers who had previously dealt with this topic. On the other hand, the scientific justification of this research is also reflected in what it will contribute to the development of methodology as a science. This development will contribute to the application of the aforementioned methods in the research of topics that are still insufficiently explored in scientific circles and will contribute to the development of other sciences in the field of human resources management, to certain areas of management, such as communication, organizational behavior and change management.

\section{CONCLUSION}

This research is socially justified because it will provide results on the basis of which concrete actions could be undertaken aimed at improving the current situation, that is, actions aimed at raising awareness of working and social organizations in improving working conditions, working climate and increasing the level of employees' satisfaction working organizations, as well as more active involvement of the community in problem solving. With the help of the results obtained by this research, it could influence the improvement of the factors that influence the increase in employees' satisfaction with their workplaces.

\section{REFERENCES}

1. Andevska M, Kudačina M, (2008). Practicum from the methodology. Novi Sad: Cekom.

2. Bogićević Milikić B, Janićijević N, Petković M, (2006). Organization. Beograd: Centar za izdavačku delatnost Ekonomskog fakulteta u Beogradu.

3. Nadoveza B, (2011). Human Resources Management. Novi Sad: Cekom.

4. Ristic D, (2009). The basics of management. Novi Sad: Cekom.

5. Robins S, (2003). Organizational behavior. Englewood Cliffs, NJ: Prentice Hall.

6. Babić L, (2009). Management of education organized by University of Belgrade: Singidunum University

7. Armstrong M. A, (2001). Handbook of Human Resources Management. London: Kogan Paige

8. Dimitrovski R, (2010). Knowledge management as a business strategy. Skopje: School of Business

9. Miljević I.M, (2007). Methodology of scientific work. Pale: Faculty of Philosophy

10. Milosavljevic S. (2006) .Osnovi metodologije političkih nauka. Beograd: Službeni glasnik

11. Šušnjar, Š. (2005). Human Resource Management. Subotica: Faculty of Economics

12. Bruster, C. (2007). International Human Resource Management. London.CIPD

13. Kranet (2005). Cranet research of comparative HRM - Cranet survey on comparative HRM - International executive report. Cranfiled: Cranet.

14. Kranet (2011). Crane survey of comparative HRM Cranet survey on comparative HRM International executive report. Cranfiled: Cranet. 